\title{
No evidence of increased fire risk due to agricultural land abandonment in Sardinia (Italy)
}

\author{
C. Ricotta ${ }^{1}$, D. Guglietta ${ }^{2}$, and A. Migliozzi ${ }^{3}$ \\ ${ }^{1}$ Department of Environmental Biology, University of Rome "La Sapienza”, Rome, Italy \\ ${ }^{2} \mathrm{CNR}$, Institute for Atmospheric Pollution, Monterotondo Scalo, Italy \\ ${ }^{3}$ Department of Arboriculture, Botany and Plant Pathology, University of Naples "Federico II", Portici, Italy
}

Correspondence to: C. Ricotta (carlo.ricotta@uniroma1.it)

Received: 15 February 2012 - Revised: 31 March 2012 - Accepted: 7 April 2012 - Published: 9 May 2012

\begin{abstract}
Different land cover types are related to different levels of fire hazard through their vegetation structure and fuel load composition. Therefore, understanding the relationships between landscape changes and fire behavior is of crucial importance for developing adequate fire fighting and fire prevention strategies for a changing world. In the last decades the abandonment of agricultural lands and pastoral activities has been the major driver of landscape transformations in Mediterranean Europe. As agricultural land abandonment typically promotes an increase in plant biomass (fuel load), a number of authors argue that vegetation succession in abandoned fields and pastures is expected to increase fire hazard. In this short paper, based on 28493 fires in Sardinia (Italy) in the period 2001-2010, we show that there is no evidence of increased probability of fire ignition in abandoned rural areas. To the contrary, in Sardinia the decreased human impact associated with agricultural land abandonment leads to a statistically significant decrease of fire ignition probability.
\end{abstract}

\section{Introduction}

Wildland fires affect large areas and cause serious damage, having ecological, social and economic consequences. Every year roughly 45000 wildfires occur in Southern Europe (Camia et al., 2008), leading to very high costs for firefighting and prevention and for damages caused by fire.

In the Mediterranean Basin, where most fires are of human origin, fire behavior is affected to some extent by the different land use and land cover (LULC) types (Nunes et al., 2005; Bajocco and Ricotta, 2008; Catry et al., 2009). This is because, on one hand, fire has been traditionally used as a land management tool, e.g. for creating pastures or eliminating agricultural waste (Carmona-Moreno et al., 2005; Moreira et al., 2009). On the other hand, different LULC types are subject to different levels of human pressure and thus to different levels of ignition risk related to anthropogenic fires of intentional or accidental origin (Bajocco et al., 2011).

From a biological viewpoint, as fuel availability and flammability are among the most important factors influencing fire ignition and propagation, different LULC types are related to different fire behavior through changes in vegetation cover and structure, which are the only fire-related landscape variables that can be manipulated (Moreira et al., 2011). Accordingly, understanding the role of LULC changes in driving fire behavior has become a major concern for defining landscape management guidelines and policies aimed at reducing fire risk and hazard.

In a recent review on landscape - wildfire interactions in Southern Europe, Moreira et al. (2011) argue that LULC changes that occurred in the last decades in Mediterranean Europe have been generally increasing fire hazard. This effect is mainly due to the increased cover of forests and shrublands in areas with former lower fuel loads, like agriculture or pastures (see Moreira et al., 2011; Pausas and FernándezMuñoz, 2012 and references therein).

Following Moreira et al. (2011), in this paper we will define fire risk or ignition risk as "the chance of a fire starting as determined by the presence and activity of any causative agent" (FAO, 1986; NWCG, 2006) and fire hazard as "a fuel complex, defined by volume, type, condition, arrangement, and location that determines the degree of ease of ignition and the resistance to control" (Moreira et al., 2011; Hardy, 2005). 
Accordingly, while fire risk embodies a clear and simple probabilistic/frequentistic concept (i.e. the chance that a fire might start, independently of how large the fire will be), fire hazard is a more complex concept that is related to the potential fire behavior for a fuel type, thus including the probability that an ignition will result in a large burned area. In this sense, as fire hazard is, by definition, tightly connected to biomass availability, the observation that the rural exodus increases fire hazard due to the increased fuel load in the abandoned areas is not really surprising, adding little to our knowledge on the influence of landscape change on fire behavior. By contrast, in this short paper, focusing on fire risk rather than on fire hazard, we argue that there is no evidence of increased probability of fires starting in Sardinia (Italy) in the period 2001-2010 due to agricultural land abandonment.

\section{Study area}

The island of Sardinia is located between $38^{\circ} 51^{\prime} \mathrm{N}$ and $41^{\circ} 15^{\prime} \mathrm{N}$ latitude and between $8^{\circ} 8^{\prime} \mathrm{E}$ and $9^{\circ} 50^{\prime} \mathrm{E}$ longitude, and covers roughly $24235 \mathrm{~km}^{2}$ (Fig. 1). Sardinia is characterized by a complex physical geography with a prevalently hilly topography and high heterogeneity in geological and morphological features. The highest elevation is $1834 \mathrm{~m}$; average elevation is $338 \mathrm{~m}$. The climate is predominantly Mediterranean, with the highest temperatures and lowest rainfall in the summer months. Average annual rainfalls range from less than $500 \mathrm{~mm}$ along the coast to roughly $900 \mathrm{~mm}$ in the inner mountainous regions. Mean annual temperatures range from 11 to $17^{\circ} \mathrm{C}$. In the coastal areas land cover is dominated by sclerophyllous shrubs, thermomediterranean Quercus ilex forests, and agricultural lands that cover about $45 \%$ of the island. Most urban areas are located in the coastal zone. The inner regions host Quercus ilex and $Q$. suber forests, together with pastures and shrublands. At higher elevations the principal forest formations are mainly composed of meso-mediterranean deciduous oaks, like Q. congesta and Q. ichnusae (Bajocco et al., 2010).

\section{Materials and methods}

To summarize landscape changes in Sardinia, we used two CORINE land-cover maps of the study area (EEA, 2000) updated for the reference years 1990 and 2006 (in the remainder CLC1990 and CLC2006, respectively). By crosstabulation of the CLC1990 and CLC2006 maps, we generated a Boolean landscape change map containing the following categories: (i) vegetation regrowth (i.e. all polygons that involve a transition from agricultural lands and pastures to shrublands and forests with a potential increase in plant biomass), and (ii) other. We included in the first class all landscape transitions between 1990 and 2006 from the agricultural areas and pastures (CLC classes 2.1, 2.2, 2.3 and 2.4) to forests (3.1) and shrublands $(3.2 .3,3.2 .4)$, together with all

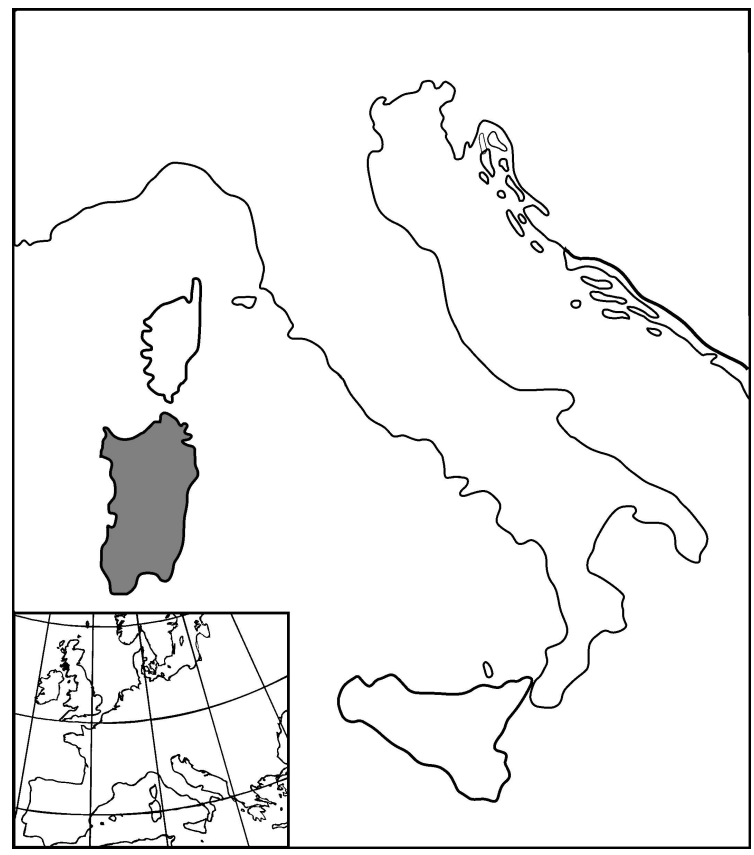

Fig. 1. Location of the study area.

transitions, from natural grasslands (3.2.1) and shrublands to forests. All these landscape changes are usually associated with the abandonment of agriculture and pastoral activities, and imply a regrowth of natural vegetation with a potential increase in fuel load due to secondary succession.

From the fire database of the Regional Forest Service of Sardinia, we extracted the geographic coordinates of the ignition points of all 28493 fires that occurred in the study area in the period 2001-2010 (Fig. 2). The ignition points were then overlaid on the landscape change map and the number of fires $N$ within the vegetation regrowth polygons was computed.

To determine whether fire risk (i.e. the number of ignitions) in the regrowth polygons is significantly different from random, we used the test developed by Bajocco and $\mathrm{Ri}$ cotta (2008). In summary, a distribution of $N$ under the null hypothesis of random occurrence of fires across the landscape is generated by randomly reassigning 9999 times all fires to both Boolean land-cover classes, such that the probability of the assignment of each fire to a given class is kept equal to the proportional extent of that class. The value of $N$ is calculated for each randomization and P-values (twotailed test) are computed as the proportion of the $\mathrm{N}$-values obtained by randomization, which are either as extreme or more extreme than the actual value of $N$. We also run the same analysis on the subset of 14116 ignition points that occurred in the regrowth polygons in the period 2006-2010 (i.e. in a time window that is successive to all land cover changes mapped). 


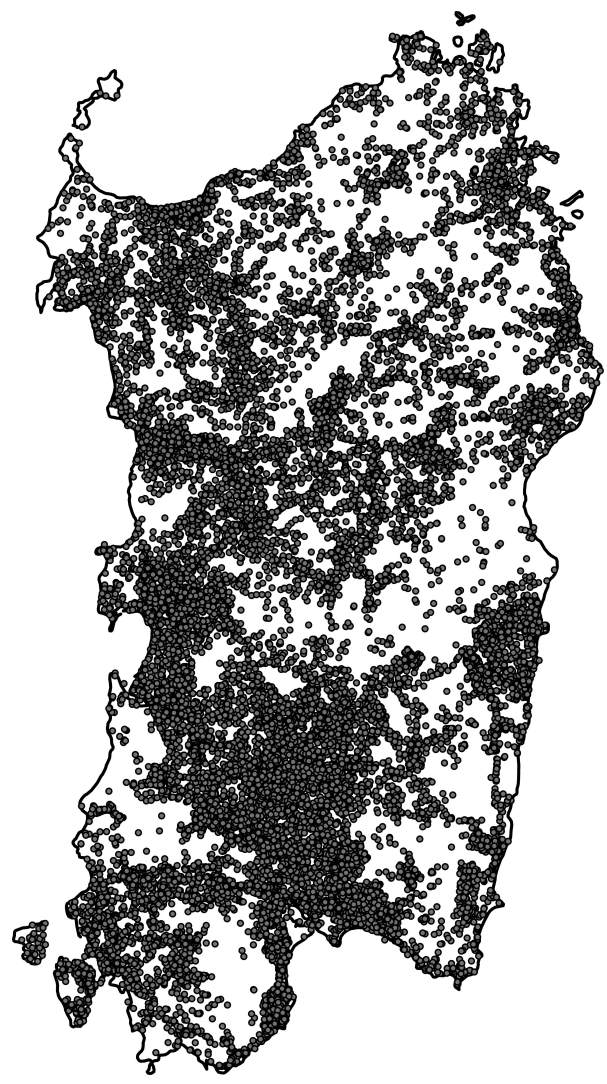

Fig. 2. Distribution of wildfires in the study area between 2001 and 2010 .

\section{Results and discussion}

The amount of landscape change associated with agricultural abandonment between 1990 and 2006 was equal to $882.88 \mathrm{~km}^{2}$, which is roughly $3.64 \%$ of the island surface. In the decade 2001-2010, the actual number of fires, $N$, in the regrowth polygons was equal to 714 , which represents $2.51 \%$ of the total amount of fires. Likewise, in the five years 2006-2010, the number of fires in the regrowth polygons was equal to 297 (i.e. roughly $2.10 \%$ of total fire number).

In both periods, the actual number of fires in the regrowth polygons was significantly lower than the corresponding number of fires expected under the null hypothesis of random fire occurrence (i.e. 1037 and 514 for the periods 2001-2010 and 2006-2010, respectively; $P<0.001$ for both data sets). That is, land cover change due to agricultural land abandonment is associated with a statistically significant decrease of fire ignition probability. The same results hold if we focus solely on the regrowth polygons that originate from the CLC classes like pastures, natural grasslands and shrublands that are located in the more marginal areas of Sardinia, where agricultural land abandonment, including the decline of pastoral activities, is more widespread (data not shown here). Unfortunately, the positional accuracy of the ignition points and the cartographic accuracy of the CORINE maps are both unknown. While these ambiguities may of course alter the strength of our results, we believe the results obtained are clear enough, even in the absence of an accurate analysis of data uncertainties.

While apparently contradictory, our results are complementary rather than opposite to the findings of Moreira et al. (2011). Like in all regions where most fires are of human origin, in Sardinia fire ignitions are mostly influenced by anthropogenic activities (Nunes et al., 2005; Bajocco and Ricotta, 2008; Catry et al., 2009; Moreira et al., 2010; Conedera et al., 2011). Therefore, as agricultural land abandonment is usually associated with decreased human pressure, not surprisingly, this process will lead to a decrease in fire ignition probability.

Although this apparent contradiction between increased fire hazard linked to the rural abandonment and the reduced fire risk linked to reduced human pressure was already hypothesized by Koutsias et al. (2010) and Moreira et al. (2011), to the best of our knowledge, this is the first time that this effect is demonstrated with real data. As a rule of the thumb, focusing on fire risk at the rural/forest interface, wherever land cover types of high human impact expand at the expenses of the surrounding natural areas, fire risk tends to increase (see Lampin-Maillet et al., 2010); on the contrary, wherever the natural vegetation colonizes areas of higher human impact, fire risk is more likely to decrease (Guglietta et al., 2011).

On the other hand, while fire ignition is principally related to human pressure, fire spread is mainly controlled by different factors, such as weather conditions, time lag until detection and intervention, topography and fuel (i.e. vegetation) type. Bajocco and Ricotta (2008) and Pezzatti et al. (2009) already emphasized the influence of vegetation type on fire size in Sardinia (Italy) and Ticino (Switzerland), while for Portugal Moreira et al. (2010) found that larger fires are more likely to occur in shrublands and forests. Accordingly, across the territory, the areas that experience the highest frequency of ignitions usually differ from those where larger fires occur (Moreira et al., 2010). As a result, due to the decreased anthropogenic pressure, areas of agricultural land abandonment are subject (at least in our case) to reduced fire risk; at the same time, due to the increased plant biomass and fuel load, fire ignitions in these areas are more likely to turn into large fires (see Bajocco and Ricotta, 2008).

To conclude, as fire ignition and size are generally driven by different factors, it is prudent to analyze these two components of fire behavior separately. We hope this suggestion will contribute to the construction of a comprehensive socio-ecological framework within the context of a complex and plural assessment of fire behavior.

Edited by: R. Lasaponara

Reviewed by: two anonymous referees 


\section{References}

Bajocco, S. and Ricotta, C.: Evidence of selective burning in Sardinia (Italy): which land-cover classes do wildfires prefer?, Landsc. Ecol., 23, 241-248, 2008.

Bajocco, S., Rosati, L., and Ricotta, C.: Knowing fire incidence through fuel phenology: a remotely sensed approach, Ecol. Model., 221, 59-66, 2010.

Bajocco, S., Salvati, L., and Ricotta, C.: Land degradation versus fire: A spiral process?, Prog. Phys. Geogr., 35, 3-18, 2011.

Camia, A., San-Miguel-Ayanz, J., Kucera, J., Amatulli, G., Boca, R., Libertà, G., Durrant, T., Schmuck, G., Schulte, E., and Bucki, M.: Forest Fires in Europe 2007, Joint Research Centre - Institute for Environment and Sustainability, Office for Official Publications of the European Communities, Luxembourg, 2008.

Carmona-Moreno, C., Belward, A., Malingreau, J. P., Hartley, A., Garcia-Alegre, M., Antonovskiy, M., Buchshtaber, V., and Pivoravov, V.: Characterizing interannual variations in global fire calendar using data from Earth observing satellites, Global Change Biol., 11, 1537-1555, 2005.

Catry, F. X., Rego, F. C., Bação, F., and Moreira, F.: Modelling and mapping wildfire ignition risk in Portugal, Int. J. Wildland Fire, 18, 921-931, 2009.

Conedera, M., Torriani, D., Neff, C., Ricotta, C., Bajocco, S., and Pezzatti, G. B.: Using Monte Carlo simulations to estimate relative fire ignition danger in a low-to-medium fire-prone region, Forest Ecol. Manage., 261, 2179-2187, 2011.

EEA: CORINE land cover technical guide, Technical report no. 40, European Environmental Agency, Copenhagen, 2000.

FAO: Wildland Fire Management Terminology. FAO Forestry Paper 70, Food and Agriculture Organization of the United Nations, Rome, 1986.

Guglietta, D., Conedera, M., Mazzoleni, S., and Ricotta, C.: Mapping fire ignition risk in a complex anthropogenic landscape, Remote Sens. Lett., 2, 213-219, 2011.
Hardy, C.: Wildland fire hazard and risk: problems, definitions, and context, Forest Ecol. Manage., 211, 73-82, 2005.

Koutsias, N., Martínez-Fernández, J., and Allgower, B.: Do factors causing wildfires vary in space? Evidence from geographically weighted regression, GISci. Remote Sens., 47, 221-240, 2010.

Lampin-Maillet, C., Jappiot, M., Long, M., Bouillon, C., Morge, D., and Ferrier, J. P.: Mapping wildland-urban interfaces at large scales integrating housing density and vegetation aggregation for fire prevention in the South of France, J. Environ. Manage., 91, 732-741, 2010.

Moreira, F., Vaz, P., Catry, F., and Silva, J. S.: Regional variations in wildfire susceptibility of land-cover types in Portugal: implications for landscape management to minimize fire hazard, Int. J. Wildland Fire, 18, 563-574, 2009.

Moreira, F., Catry, F. X., Rego, F., and Bacao, F.: Size-dependent pattern of wildfire ignitions in Portugal: when do ignitions turn into big fires?, Landsc. Ecol., 25, 1405-1417, 2010.

Moreira, F., Viedma, O., Arianoutsou, M., Curt, T., Koutsias, N., Rigolot, F., Barbati, A., Corona, P., Vaz, P., Xanthopoulos, G., Mouillot, F., and Bilgili, E.: Landscape - wildfire interactions in southern Europe: Implications for landscape management, J. Environ. Manage., 92, 2389-2402, 2011.

Nunes, M. C. S., Vasconcelos, M. J., Pereira, J. M. C., Dasgupta, N., and Alldredge, R. J.: Land cover type and fire in Portugal: do fires burn land cover selectively?, Landsc. Ecol., 20, 661-673, 2005.

NWCG: Glossary of Wildland Fire Terminology. National Wildfire Coordinating Group, PMS 205, Boise, Idaho, 2006.

Pausas, J. G. and Fernández-Muñoz, S.: Fire regime changes in the Western Mediterranean Basin: from fuel-limited to droughtdriven fire regime, Climatic Change, 110, 215-226, 2012.

Pezzatti, G. B., Bajocco, S., Torriani, D., and Conedera, M.: Selective burning of forest vegetation in Canton Ticino (Southern Switzerland), Plant Biosyst., 143, 609-620, 2009. 